\title{
LMA observations of upward lightning flashes at the Säntis Tower initiated by nearby lightning activity
}

\author{
Antonio Sunjerga $^{\mathrm{a}, *}$, Marcos Rubinstein ${ }^{\mathrm{b}}$, Nicolau Pineda ${ }^{\mathrm{c}, \mathrm{d}}$, Amirhossein Mostajabi $^{\mathrm{a}}$, \\ Mohammad Azadifar $^{\mathrm{b}}$, David Romero ${ }^{\mathrm{d}}$, Oscar Van der Velde ${ }^{\mathrm{d}}$, Joan Montanya ${ }^{\mathrm{d}}$, \\ Jordi Figueras i Ventura ${ }^{\mathrm{e}}$, Nikola Besic ${ }^{\mathrm{e}}$, Jacopo Grazioli ${ }^{\mathrm{e}}$, Alessandro Hering ${ }^{\mathrm{e}}$, Urs Germann ${ }^{\mathrm{e}}$, \\ Gerhard Diendorfer ${ }^{\mathrm{f}}$, Farhad Rachidi ${ }^{\mathrm{a}}$
}

a Electromagnetic Compatibility Laboratory, Swiss Federal Institute of Technology (EPFL), Lausanne, 1015, Switzerland

${ }^{\mathrm{b}}$ University of Applied Sciences of Western Switzerland (HES-SO), Yverdon-les-Bains, 1400, Switzerland

${ }^{\mathrm{c}}$ Meteorological Service of Catalonia, Carrer Berlín 38-46, Barcelona, 08029, Spain

${ }^{\mathrm{d}}$ Lightning Research Group, Technical University of Catalonia, Edifici TR1, Carrer Colom 1, Terrassa, 08222, Spain

${ }^{\mathrm{e}}$ MeteoSwiss, Locarno, Switzerland

${ }^{\mathrm{f}}$ OVE Service GmbH, Dept. ALDIS (Austrian Lightning Detection \& Information System), Vienna, Austria

\section{A R T I C L E I N F O}

\section{Keywords:}

Lightning

Lightning Mapping Array

Other-triggered lightning

Current

Charge structure

Leader polarity

Radar

Electric field

\begin{abstract}
A B S T R A C T
We present in this paper lightning current measurements, LMA (Lightning Mapping Array) data and fast antenna electric fields associated with upward flashes observed at the Säntis Tower during summer of 2017. The LMA network consists of six stations that were installed in the vicinity of the tower at distances ranging from $100 \mathrm{~m}$ to $11 \mathrm{~km}$ from it. Out of 20 LMA recorded flashes here we analyze in detail three so-called 'other-triggered flashes', triggered by preceding activity. Based on the lightning activity derived from the European Lightning Detection Network (EUCLID) in an area within $30 \mathrm{~km}$ from the tower and within a 1-s time window before the start of the upward tower flashes, only one out of 20 flashes was classified as 'other-triggered'(OT). However, the investigations based on the LMA data reveal that 3 more flashes of the 20 analyzed were preceded by nearby activity and should therefore be classified as OT flashes. We analyze conditions conducive to the OT flashes, such as the charge structure of the clouds, polarity of preceding leaders and level of activity of the storm.

The LMA source active time period was on average seven times higher for the OT flashes than that for selfinitiated flashes.
\end{abstract}

\section{Introduction}

The characteristics of upward lightning discharges based on tall structure measurements (e.g., Gaisberg, Peissenberg, Säntis) have been widely reported in the literature [1]. However, their initiation mechanisms are not well understood and are still under investigation. Wang et al. [2] proposed the classification of upward flashes into two categories: self-triggered (ST) and other-triggered (OT), based on the absence or the presence of other lightning activity in the geographical and temporal vicinity of the tower-initiated flash. The number of ST and OT flashes has been shown to vary depending on the geographical area (e.g., [3]). It has also been shown that the rate of ST versus that of OT flashes is correlated, to some extent, to atmospheric conditions $[4,5]$. Different observation methods have been used to classify flashes into the ST and OT categories, namely based on data from lightning location systems (LLS) [3], electric fields [6], and video observations [7].

OT flashes can be preceded (or triggered) by both in-cloud (IC) and cloud-to-ground (CG) flashes. IC flashes can occur on both large scales (a few tens of $\mathrm{km}$ ) and small scales (a few hundreds of meters), while CG channels extend to a few kilometers [8]. Schumann et al. [9], using video observations, proposed different mechanisms conducive to the initiation of upward flashes, all of them associated with horizontally propagating leaders in the clouds over the towers.

A Lightning Mapping Array (LMA) is a 3D discharge location system pioneered by D. E. Proctor [10-12]. The detection is accomplished by measuring the VHF radiation from the discharges, while the location is determined using the measured arrival times of the common signal at each station to calculate the spatial position and emission time of the radiation source. Proctor used 5 stations to study small-scale

\footnotetext{
* Corresponding author.

E-mail address: antonio.sunjerga@epfl.ch (A. Sunjerga).
} 
breakdowns of lightning. Clustering algorithms [13-15] can be used to automatically identify lightning flashes from LMA data.

In June 2017, a 3D LMA network [16,17], consisting of 6 stations belonging to the Lightning Research Group of the Polytechnic University of Catalonia (UPC) was installed around the Säntis Tower in Northeastern Switzerland. The covered range is typically about $60 \mathrm{~km}$ in diameter. The Säntis Tower is equipped with a direct current measuring system since May 2010. The LMA was operational during two months, July and August, 2017.

Out of a total of 20 recorded flashes, we analyze in detail in this paper three flashes for which simultaneous measurements of current and LMA sources associated with OT upward flashes from the Säntis Tower were obtained during the 2017 campaign. This paper is an extended version of paper [18].

\section{Measurement setup}

\subsection{Lightning current and electric field measurements}

The 124-m tall Säntis Tower, located at $47^{\circ} 14^{\prime} 57^{\prime \prime} \mathrm{N}$ and $9^{\circ} 20^{\prime} 32^{\prime \prime} \mathrm{E}$, is by far the most frequently struck structure in Switzerland [19,20]. The tower has been instrumented since May 2010 using advanced equipment including remote monitoring and control capabilities for accurate measurement of lightning current parameters enabling a highresolution sampling of lightning currents over long observation windows [19,21]. Lightning currents are measured using two sets of Rogowski coils and multigap B-dot sensors located at two different heights along the tower. The analog outputs of the sensors installed are relayed to a digitizing system by means of optical fiber links. The system is equipped with GPS and allows over-the-Internet remote maintenance, monitoring, and control. More details on the instrumentation can be found in Ref. [19,21-24]. The lightning current is recorded over a $2.4 \mathrm{~s}$ interval with a pre-trigger delay of $960 \mathrm{~ms}$.

The Säntis measurement station includes also an electric field measurement station comprising a flat-plate antenna and an analog integrator with an overall frequency bandwidth of $30 \mathrm{~Hz}-2 \mathrm{MHz}$, located in Herisau at a distance of $14.7 \mathrm{~km}$ from the tower [25].

\subsection{Lightning Mapping Array (LMA)}

An LMA network was installed in the Säntis Tower region in June 2017 [26]. The system consists of six stations measuring VHF radiation in the $60-66 \mathrm{MHz}$ band. The locations of the LMA stations were chosen considering several factors, namely:

1) The magnitude of the local noise within the frequency band,

2) The availability of reliable AC power and communication means,

3) The distance to the source (Säntis Tower), and,

4) A good combination of accessibility and security.

The selected locations correspond to mobile base stations belonging to Swisscom and Swisscom Broadcast and they are shown in Fig. 1. The measurement stations were deployed in the vicinity of the Säntis Tower, at distances ranging from $100 \mathrm{~m}$ to $11 \mathrm{~km}$. The area of interest is located in eastern Switzerland and it covers parts of the cantons of Appenzell Inner-Rhodes, Appenzell Outer-Rhodes, and St. Gallen. The LMA takes the maximum power of VHF radiation within a time window of $80 \mathrm{~ms}$ and measures the time of arrival with 50 ns accuracy using a PC-based digitizer card coupled to a GPS receiver.

The LMA data were synchronized with the lightning current data using GPS time stamps. Results from the LMA network were transformed from global coordinates to the local coordinate system of the tower taking into account the curvature of the Earth. The coverage of the LMA system is about $30 \mathrm{~km}$ to the west of the tower, about $15 \mathrm{~km}$ to the east and $25 \mathrm{~km}$ to the south and north (for more details see [27]).

\section{Observations of Other-triggerd flashes}

\subsection{Overall data}

During the campaign, lightning currents, electric fields and LMA data were simultaneously recorded. In this paper, we present results for 20 analyzed flashes in the period from 29.06.2017 to 18.07.2017. The electric field system was operational only during three of the flashes (\#18, \#19 and \#20 in Table 1). Using the data from the EUCLID network [28], the flashes were classified either as OT or ST, considering whether or not lightning activity was reported in an area within $30 \mathrm{~km}$ from the tower and within a 1-s time window before the start of the tower flash. The time interval criterion of 1-s was chosen because most of the flashes last less than a second [29] so we can take into account all the activity that could still occur after the recorded pulse by EUCLID. It is worth noting that the value of the inter-flash intervals recorded by EUCLID during the storms in the $30-\mathrm{km}$ range around the Säntis Tower is observed to have a median of about $5 \mathrm{~s}$ [30]. Using these criteria, all 20 flashes (18 negative, 1 positive and 1 bipolar) were initially classified as ST in Ref. [18]. A high level of noise in the low frequency spectrum of the Rogowski coil lightning measuring system made it hard to determine the exact current onset time at the tower. A more detailed analysis with application of a lowpass filter in this paper showed that one flash in Ref. [18] was misclassified using EUCLID as an ST flash. That upward negative flash was preceded by a downward, single-stroke positive flash recorded about $100 \mathrm{~ms}$ before the start of the ICC (initial continuous current), about $22 \mathrm{~km}$ East and $11 \mathrm{~km}$ South of the tower, in an area without LMA coverage. Since the preceding event was not in the area of LMA coverage, the flash from the tower was not classified as OT using the LMA.

On the other hand, using the LMA, we could observe that 3 more flashes were of the OT type. Schumann et al. [31] observed three different types of preceding flashes from which the upward lightning can be triggered: (i) a return stroke (RS) that leads to an intensification of a horizontal leader over the tower that, in turn, triggers the upward lightning from the tower, (ii) an extension over the tower of the horizontal part of a leader during the continuing current (CC) phase of a nearby CG flash, and (iii) an in-cloud leader that develops over the tower, and whose other end may or may not terminate in the ground. All three LMA-recorded OT flashes belong to category (iii) and, consequently, are of the type not often recognized by lightning location systems, as they detect lightning in the LF frequency range and are mostly effective in detecting CG discharges and cloud discharges whose channel has a vertical orientation. It is unclear to which type the OT flash recognized by EUCLID belongs since the LMA did not detect any activity over the tower at the time of initiation of the upward flash. Note that the preceding RS is located outside of the coverage area of the LMA.

In what follows, we will present one positive OT flash and two negative OT flashes that occurred during a period of just $3 \mathrm{~min}$. Data for the third negative OT flash classified by EUCLID will not be shown here since, as mentioned, the preceding flash was not covered by the LMA. However, the available data can be found in the attached materials. The time evolution of LMA sources for each flash can also be observed in the accompanying animations. We will analyze the charge structure of the cloud as well as the polarity of the leaders.

Since the negative leaders propagate through positive charge regions and radiate more strongly (compared to positive leaders) in the VHF spectrum [32], the LMA observations over longer periods can be used to infer the charge structure of the cloud. The average horizontal speed can be used to estimate the polarity of the leader. Van der Velde and Montanyà [33] showed that negative leaders propagate with an average speed of $10^{5} \mathrm{~m} / \mathrm{s}$ (during positive cloud to ground flashes, the speed can sometimes go up to $10^{6} \mathrm{~m} / \mathrm{s}$ ), while the average speed for positive leaders is around $2 \times 10^{4} \mathrm{~m} / \mathrm{s}$. This can also be used to infer the charge structure since, in addition to the mentioned observation in [32] that negative leaders propagate through positive regions, positive 


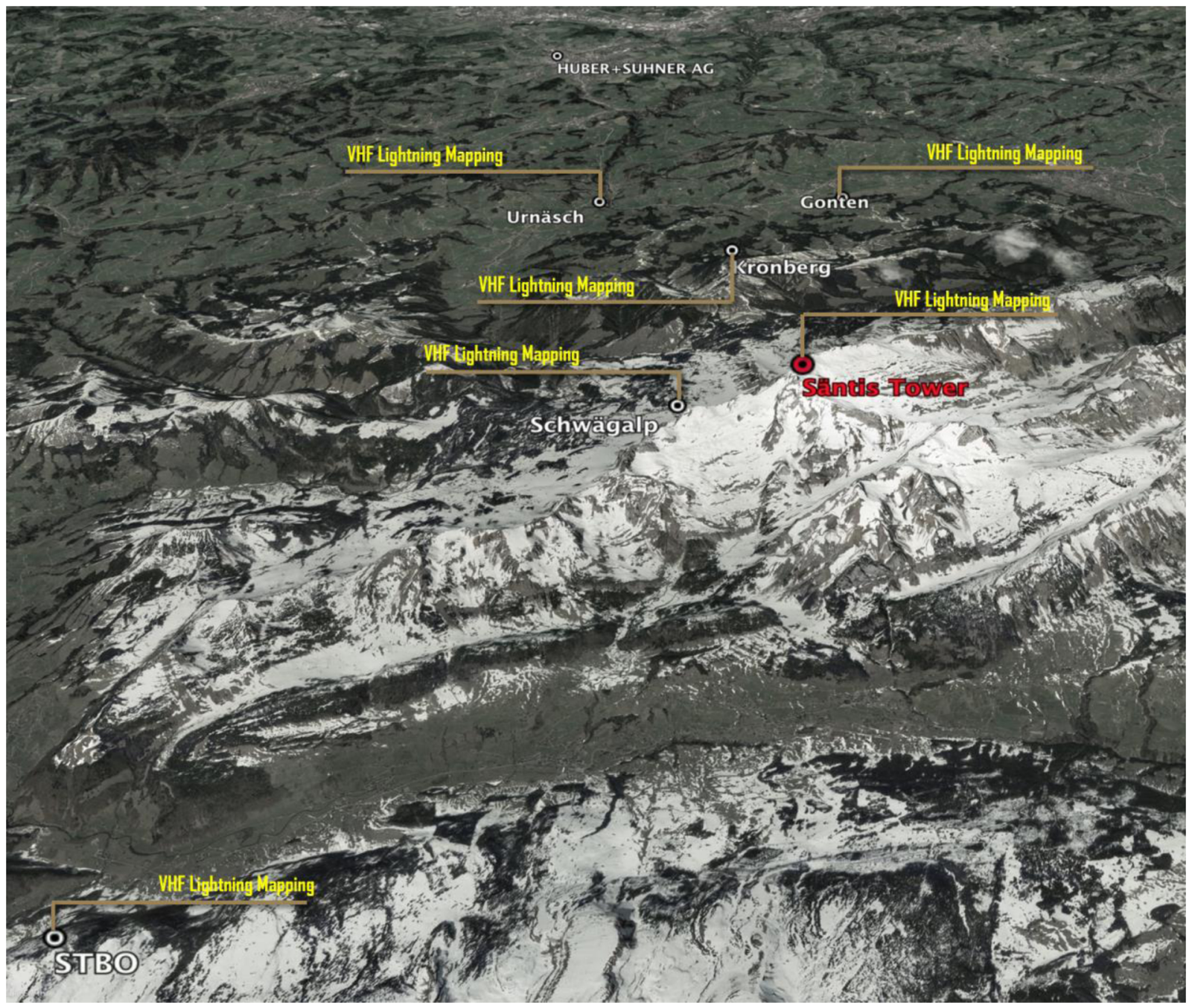

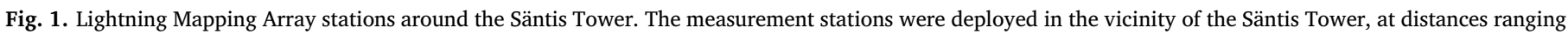

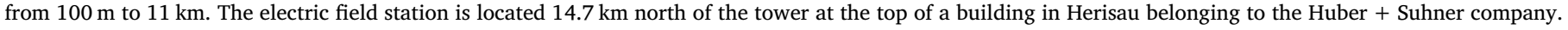

Table 1

Percentage of LMA active period (period with no more than 100 ms without LMA sources) 20 min observations centered at time of flash.

\begin{tabular}{|c|c|c|c|c|c|c|c|c|c|c|}
\hline Flash number & 1 & 2 & 3 & 4 & 5 & 6 & 7 & 8 & 9 & 10 \\
\hline Date & 29.06 .17 & 29.06 .17 & 29.06 .17 & 29.06 .17 & 29.06 .17 & 29.06 .17 & 29.06 .17 & 29.06 .17 & 29.06 .17 & 29.06 .17 \\
\hline UTC Time & $13: 38: 27$ & $14: 06: 13$ & 14:08:39 & 14:11:09 & $15: 05: 42$ & $15: 10: 52$ & $15: 36: 50$ & $15: 39: 46$ & $15: 45: 52$ & $15: 47: 31$ \\
\hline Polarity & $\mathrm{P}$ & $\mathrm{N}$ & $\mathrm{N}$ & $\mathrm{N}$ & $\mathrm{N}$ & $\mathrm{N}$ & $\mathrm{N}$ & $\mathrm{N}$ & $\mathrm{N}$ & $\mathrm{N}$ \\
\hline Type & OT & ST & ST & ST & ST & ST & ST & ST & ST & ST \\
\hline LMA Active (\%) & 3.95 & 1.67 & 1.15 & 0.83 & 0.04 & 0.05 & 0.13 & 0.18 & 0.33 & 00.33 \\
\hline Flash number & 11 & 12 & 13 & 14 & 15 & 16 & 17 & 18 & 19 & 20 \\
\hline Date & 29.06 .17 & 29.06 .17 & 29.06 .17 & 10.07 .17 & 10.07 .17 & 10.07.17 & 14.07.17 & 18.07.17 & 18.07.17 & 18.07.17 \\
\hline UTC Time & $15: 54: 55$ & $16: 00: 13$ & $16: 05: 36$ & $20: 48: 58$ & $20: 51: 45$ & $21: 19: 37$ & $13: 25: 39$ & $16: 28: 01$ & $16: 30: 58$ & $16: 50: 01$ \\
\hline Polarity & $\mathrm{N}$ & $\mathrm{N}$ & $\mathrm{N}$ & $\mathrm{N}$ & $\mathrm{N}$ & $\mathrm{N}$ & B & $\mathrm{N}$ & $\mathrm{N}$ & $\mathrm{N}$ \\
\hline Type & ST & ST & ST & ST & ST & ST & ST & OT & OT & OT \\
\hline LMA Active (\%) & 0.24 & 0.13 & 0.07 & 0.19 & 0.10 & 0.01 & 0.13 & 2.42 & 2.38 & 0.68 \\
\hline
\end{tabular}

leaders propagate through negative regions. In the following analysis, one has to bear in mind the limitation of the LMA. Mazur et al. [34] argued that the TOA lightning mapping technique does not allow the simultaneous processing of both the strong radiation signals from negative breakdowns and the much weaker radiation signals from positive breakdowns. Based on that assumption, it is not clear if any of the floating leaders occurred in a bidirectional [35] or a unidirectional manner. The LMA has also a low efficiency in detecting leaders such as dart leaders or $\mathrm{K}$ changes propagating along already ionized paths.

\subsection{Negative flashes}

\subsubsection{Charge structure}

Two negative OT flashes (\#18 and \#19 in Table 1) occurred in a time interval of just below $3 \mathrm{~min}$ and a third one (\#20 in Table 1) followed about $22 \mathrm{~min}$ after the first one. The VHF activity in the 20min period centered at the time of the first other-triggered flash is presented in Fig. 2, in which the inferred positive and negative charge regions are shown. 

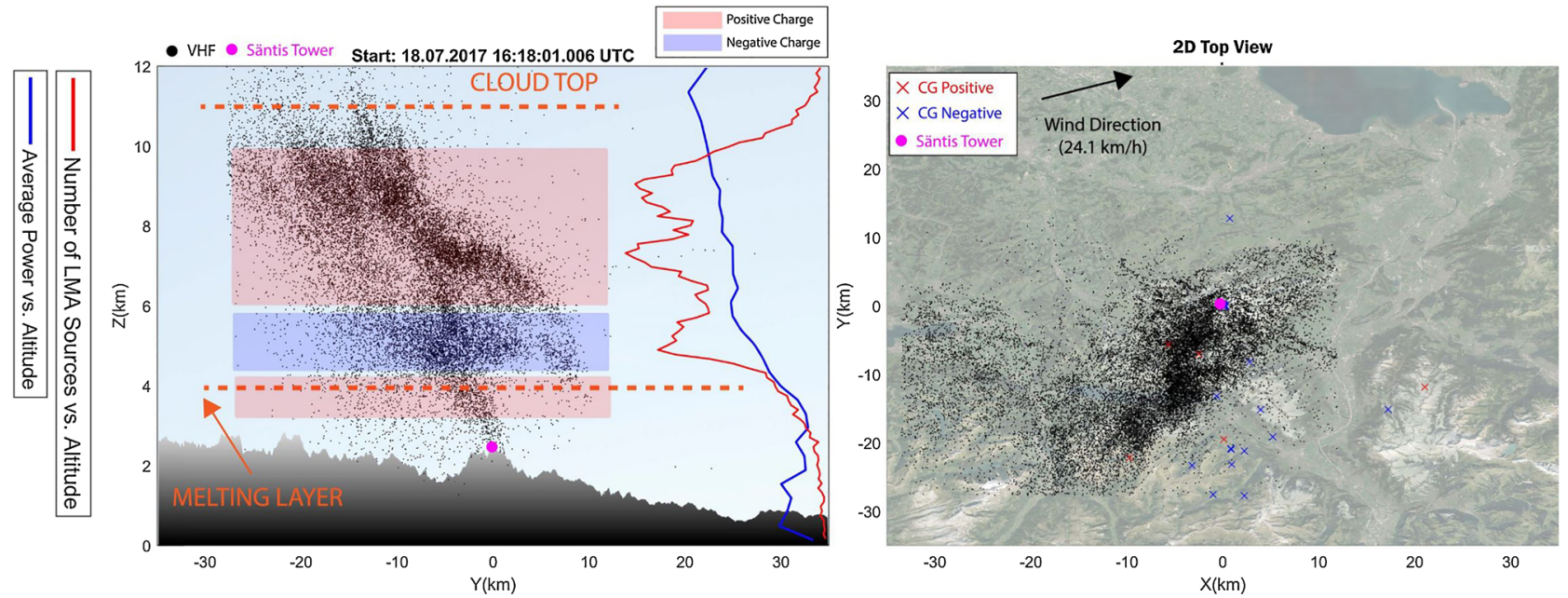

Fig. 2. VHF activity recorded by the LMA stations in the Säntis region over a 20-min time window starting 10 min prior to the initiation of two negative flashes to the tower. Left panel: 2D side view with histogram of LMA sources vs. altitude. Right panel: 2D top view. EUCLID recorded CG pulses are shown with crosses (blue for negative and red for positive). The negative and positive charge regions, inferred from the LMA source density, are shown, respectively, in blue and red in the left panel. The position of the tower is shown with a purple marker.

Radar data (see attached material) suggest that the cloud extended to a height of about $11 \mathrm{~km}$ and the melting layer can be observed at about $4 \mathrm{~km}$. It is worth noting that, based on balloon observations, a change of the charge layer sign occurs at the level of the melting layer [36,37]. The wind speed at the location of the Säntis was $24.1 \mathrm{~km} / \mathrm{h}$ with an angle of $253^{\circ}$, approximately from West (as shown with the black arrow in Fig. 2b). The temperature at the summit of the Säntis was measured to be $10.7^{\circ} \mathrm{C}$ with a relative humidity of $75 \%$. During the considered 20 -min period, EUCLID recorded in total of 158 pulses which included 29 CG pulses and 129 IC pulses. Five out of 29 CG pulses were positive while there were 98 positive pulses out of 129 in the case of the IC pulses. Note that, even though most of the EUCLID detections are strokes, we have called EUCLID detections "pulses". This is to account for the fact that EUCLID records may include, in addition to strokes, fast pulses superimposed on the ICC (the so-called ICC pulses).

In Fig. 2 we infer the charge polarity based on the density level of the LMA sources, the polarity of leaders propagating at different heights and the power of the LMA sources. A high number of LMA sources can be observed at altitudes ranging from 6 to $9.5 \mathrm{~km}$, suggesting that these altitudes correspond to the main positive charge region. Negative leaders are observed in this region.

A negative charge region just below the main positive is characterized by a lower number and power of LMA sources. Further, we assume a shallow positive region below the main negative region due to the corona discharge from the ground. The exact charge structure might be much more complex than the one presented in Fig. 2, possibly with different charge polarities at the same altitude. The inferred charge structure in Fig. 2 is based on indirect measurements that could be affected by distance to the VHF radiation sources, polarization and other uncontrolled factors and it should therefore be taken with caution.

\subsubsection{LMA observations}

Fig. 3 presents the obtained data for the first upward negative OT flash. The start of the initial continuous current (ICC) occurs at about $100 \mathrm{~ms}$ as marked with a black arrow in Fig. 3c. The flash was preceded by in-cloud discharge activity as can be seen from the LMA data (red arrows marked with number 1 ). This activity was initiated at different altitudes (from about 2 to $10 \mathrm{~km}$ ) west of the tower, propagating in different directions, south, north and east towards the tower, and presumably causing an electric field intensification at the tower tip, resulting in the initiation of an upward flash.

Fig. 4 presents the horizontal distance from the tower to the groundplane projection of the detected LMA sources as a function of time. Blue and black straight lines were drawn in the plot of Fig. 4 with slopes corresponding to the typical positive leader speed $\left(2 \times 10^{4} \mathrm{~m} / \mathrm{s}\right)$ and negative leader speed $\left(1 \times 10^{5} \mathrm{~m} / \mathrm{s}\right)$. Using the speed criteria, we can infer the leader polarity. The estimation is made somewhat difficult by the relatively low number of detected LMA sources and leader branching. The trend in the data shown in Fig. 4 is not clear in the first $80 \mathrm{~ms}$. Beyond this time, there is an indication of the characteristic horizontal speed of negative leaders. With reference to Fig. 3, the presence of the initial continuous current in the tower-base current indicates that the flash was of upward type. From the negative sign of the ICC, we can conclude that the leader was positive. No LMA sources associated with the upward leader are recorded, since they are probably obscured by stronger radiation from the negative leader (shown with the orange arrow \#2 in Fig. 3) as discussed by Mazur et al. [34].

Observations for the complete duration of the flash are shown in Fig. 5. Note that the current in Fig. $5 \mathrm{c}$ is now shown in logarithmic scale. As can be seen from Fig. 5b, the length of the in-cloud leader was more than $40 \mathrm{~km}$, covering a surface of about $800 \mathrm{~km}^{2}$. The leader propagated in various directions and it probably obscured the activity of the flash at the tower, both during the ICC and during the RS's phase. Most of the RSs were detected by EUCLID at the location of the tower. The extension of the in-cloud leader continued even after the last RS of the tower flash as can be seen from Fig. 5c. Interestingly, a positive CG flash, which presumably induced the fast current impulse at the tower, was observed by EUCLID. It is marked with the black arrow in Fig. $5 \mathrm{c}$.

Observations on the first $350 \mathrm{~ms}$ of the second negative OT flash are shown in Fig. 6. The ICC current started at about $100 \mathrm{~ms}$. Again, we can conclude from the ICC and current polarity that an upward positive leader was initiated from the tower. The LMA sources of the in-cloud leader started before the onset of the ICC (red arrows \#1), at about $25 \mathrm{~ms}$ and the slope in Fig. 7 is typical of negative polarity leaders. As in the previous flash, most of the LMA sources from the preceding negative leader were detected at an altitude of 4-7 km, suggesting that the positive charge region was at that altitude range, consistent with Fig. 2 . The upward positive leader was presumably obscured again by strong radiation from a negative in-cloud leader (orange arrow \#2). The ICC ended before the onset of the first RS and only one LMA source was recorded during the six RSs. All six RSs were recorded by EUCLID at the location of the tower, not shown in Fig. $6 \mathrm{c}$ due to the limited range in the $\mathrm{x}$ and $\mathrm{y}$ axes.

\subsubsection{Electric field vs. current}

In Figs. 8 and 9 we present the time synchronized waveforms of the electric field measured at $14.7 \mathrm{~km}$ from the tower and the current 

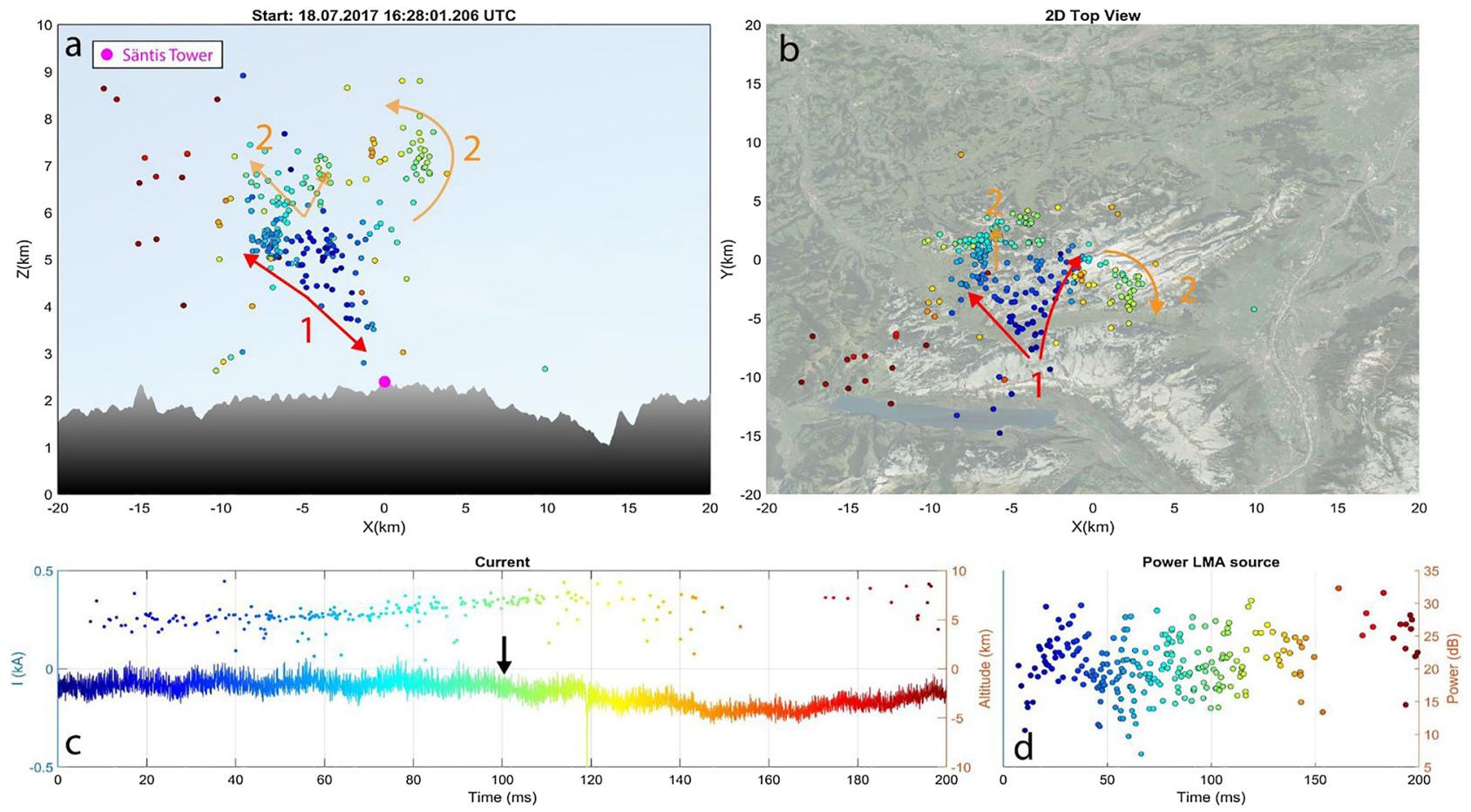

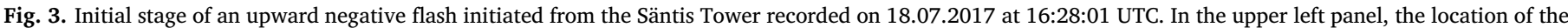

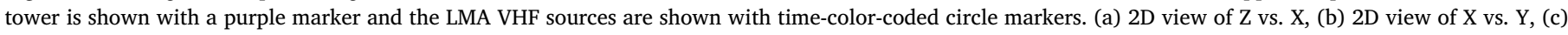

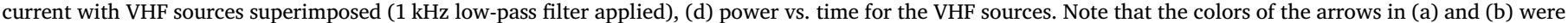

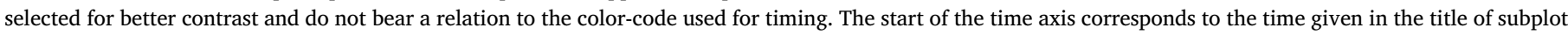
(a). The colored arrows show the development of in-cloud leaders.

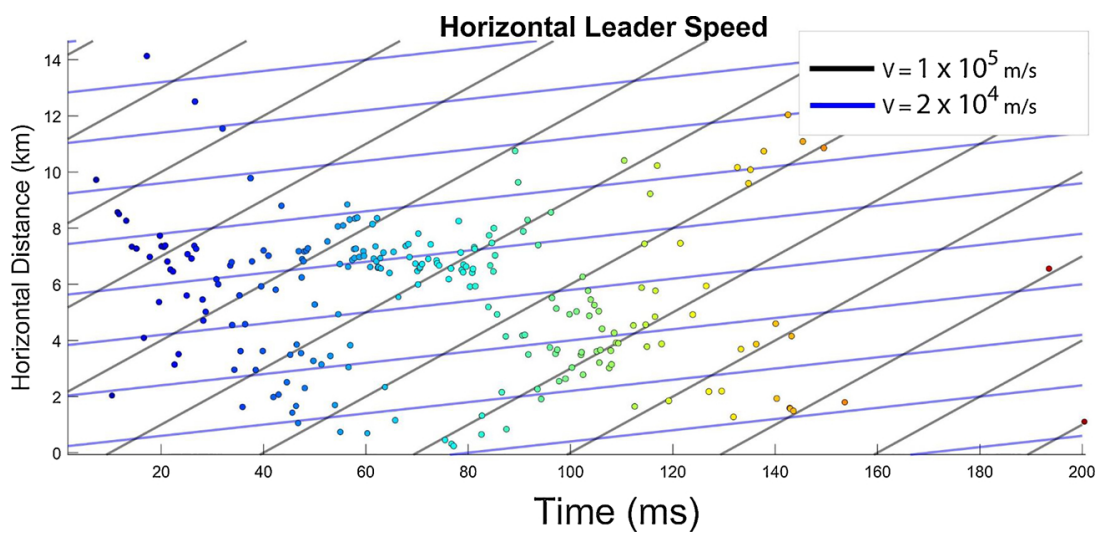

Fig. 4. Horizontal distance vs. time for LMA sources during the initial stage of the flash. The slopes of the blue and black straight lines correspond to the typical speeds of positive and negative leaders, respectively. Successive VHF sources (colored dots) are inferred to belong either to positive or to negative leaders depending on the straight line slope they roughly follow.

measured at the Säntis Tower. In both cases, we can observe the rise of the electric field, caused by the in-cloud leader, prior to the initiation of the current. The delay time of the current is consistent with the delay time from the first LMA sources measured in Figs. 3 and 6. The in-cloud leader propagated during the whole duration of the first negative flash. In the case of the second flash, the in-cloud leader ceased to exist prior to the RSs phase, which can be seen in Fig. 9.

\subsubsection{Skech of the process}

Figs. 10 and 11 show a simplified sketch of the initial stage of the two observed negative OT flashes. In the case of the first flash (Fig. 10), a leader started west of the tower at an altitude of about $5 \mathrm{~km}$ and it propagated in three different directions. Even though the polarity of the leader is not completely clear from the horizontal speed criteria, we have assumed it to be negative with possibly a positive branch to keep zero net charge [38].

The second flash started similarly west of the tower and it propagated in two directions, one horizontal above the tower and one both vertically up and horizontally. Again, we cannot rule out the existence of a positive leader in the opposite direction that was possibly obscured by the strong radiation of negative leaders. As the horizontal portion reached the region above the tower, a positive upward leader was initiated.

\subsection{Positive flash}

\subsubsection{Charge structure}

The high VHF activity in the 20-minute period centered at the time of the positive OT flash that occurred on 29.06.2017 at 13:28:27 UTC is presented in Fig. 12. Radar data (see attached material) suggest that the cloud extended to a height of about $8 \mathrm{~km}$ and the melting layer was at about $3 \mathrm{~km}$. The wind speed at the location of the Säntis was $6.1 \mathrm{~km} / \mathrm{h}$ with an angle of $186^{\circ}$, approximately from the South (as shown with a black arrow in Fig. 12b). The temperature at the altitude of the Säntis tower was $4.2{ }^{\circ} \mathrm{C}$, with a relative humidity of $100 \%$. During the considered 20-minute period, EUCLID recorded 70 CG pulses and 133 IC pulses. All 70 CG pulses where negative (some of them superimposed) 

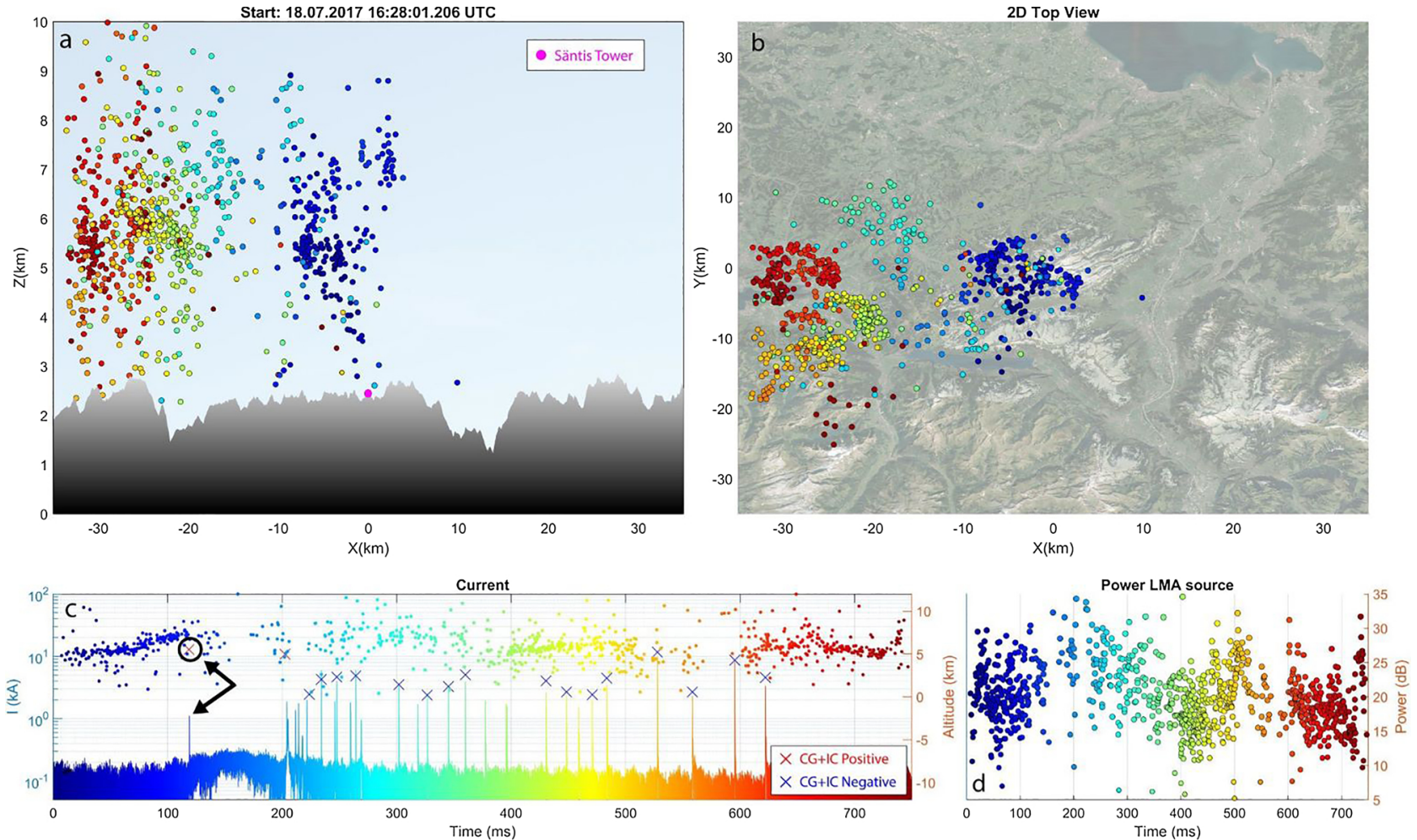

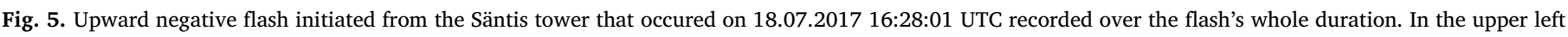

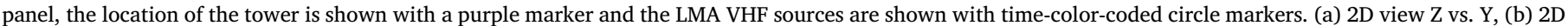
view of X vs. Y, (c) current magnitude in logarithmic scale with superimposed VHF sources, (d) power vs. time for the VHF sources.
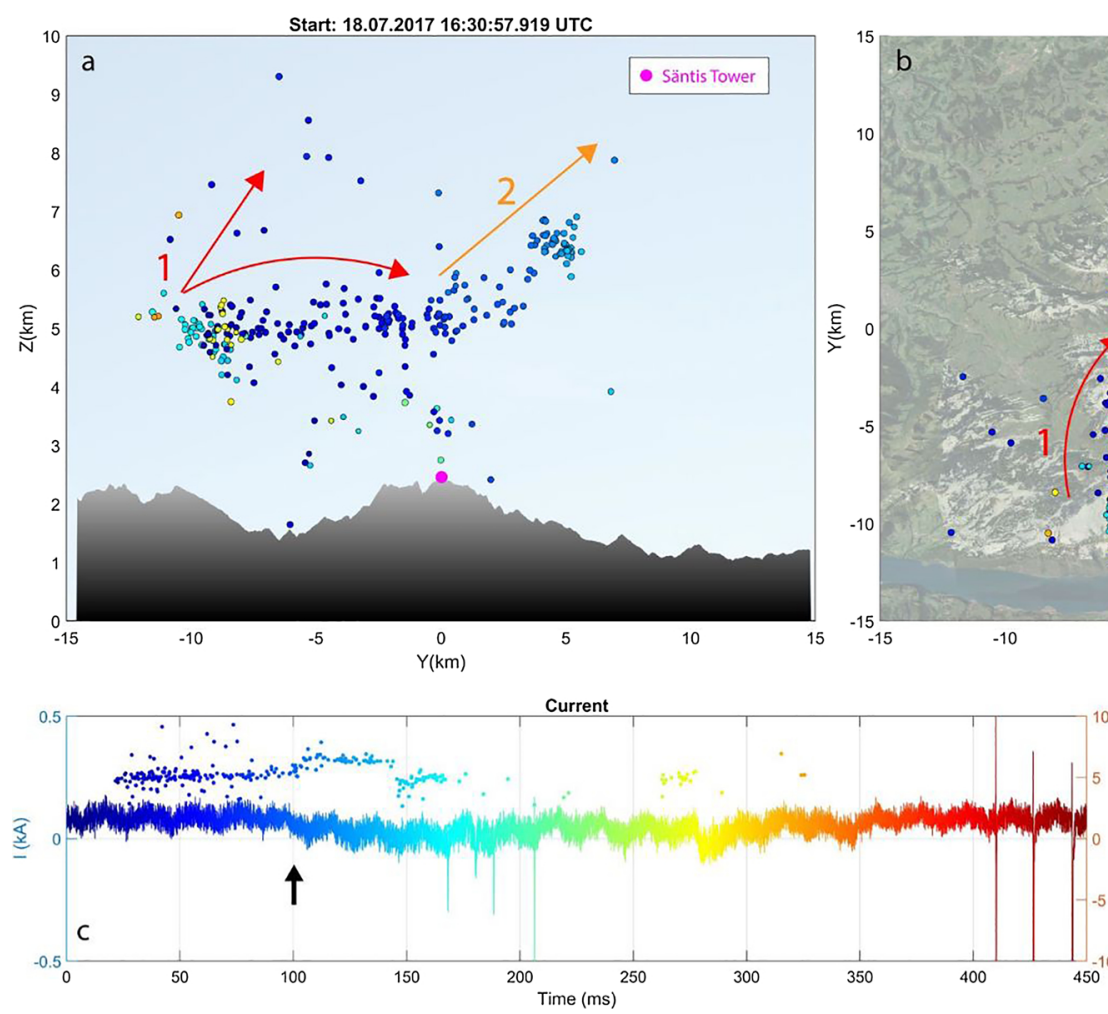
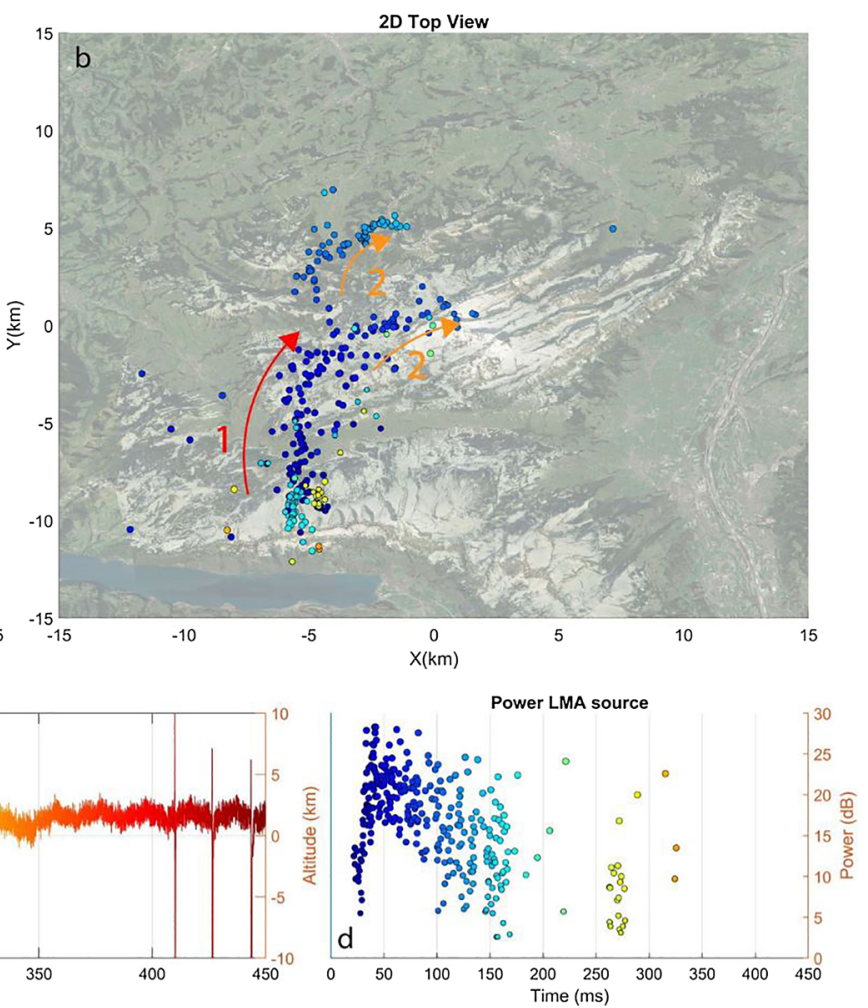

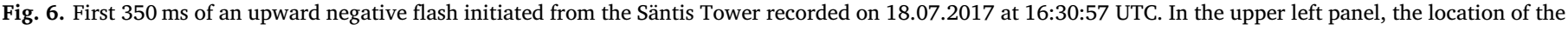

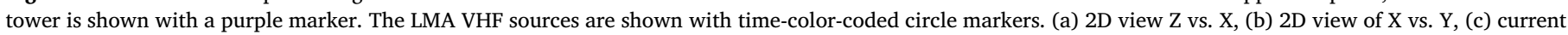

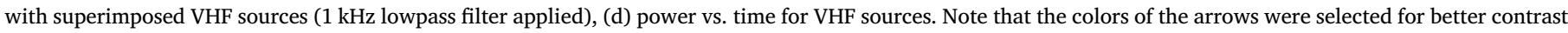
and they are independent of the colors used in the time-code. The colored arrows show the development of in-cloud leaders. 


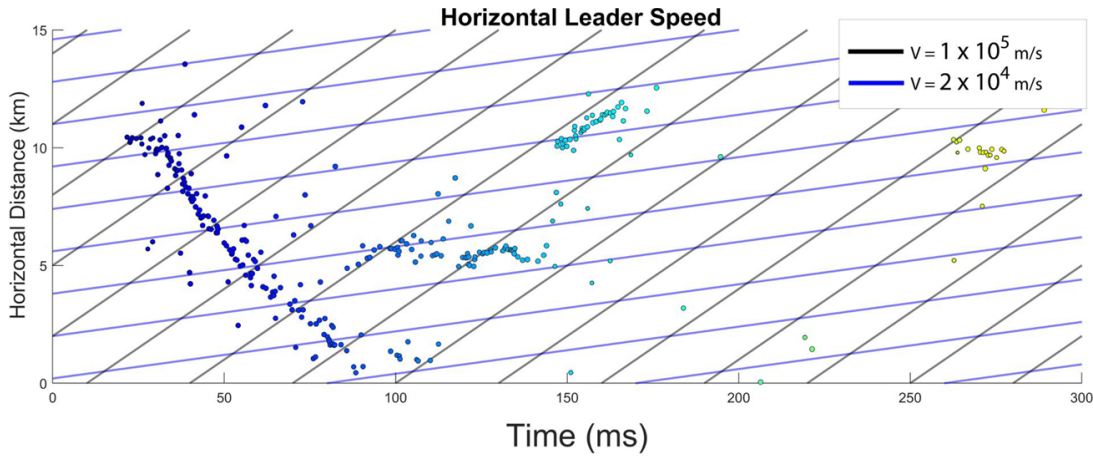

Fig. 7. Horizontal distance vs. time for LMA sources during the initial stage of the flash. The slopes of the blue and black straight lines correspond to the typical speeds of positive and negative leaders, respectively.

and 93 out of the 133 IC pulses were positive. In Fig. 12, the polarity of the charges was inferred based on the LMA sources density level, the polarity of the leaders propagating at different heights and the power of the LMA sources.

A high number of LMA sources can be observed at altitudes ranging from 3 to $5 \mathrm{~km}$, suggesting that the positive charge region was located in that height range as illustrated in Fig. 12. The negative charge layer, inferred to be above that positive charge region is suggested by the lower LMA source density and slightly lower average power of LMA sources. It is possible that there exists a positive charge region above the negative region, making the structure be similar to the normal tripole structure observed by Qie et al. [39] with a larger-than-usual lower positive charge region that, also as in this study, did not produce downward positive CG. However, this larger than usual lower positive charge region might be conducive to upward positive lightning. Since the evidence used to infer the charges is indirect and essentially limited to LMA source characteristics, the charge structure in Fig. 12 should be taken with caution. The exact charge structure might be much more complex than the one presented in Fig. 12, possibly with different charge polarities at the same altitude.

\subsection{2. $L M A$ observations}

Fig. 13 presents simultaneous measurements of current and LMA sources for the positive flash. The flash was preceded by an in-cloud leader marked with red arrows number (\#1). This leader propagated vertically to ground and branched horizontally. It was classified as negative using the criteria for the horizontal velocity (same procedure as in Figs. 4 and 7). This leader was followed immediately by the upward negative leader from the tower (arrow \#2). The polarity of this leader can be inferred from the current waveform. The positive current waveform at the tower lasted for about $6 \mathrm{~ms}$. It should be noted that it is also possible that the flash was actually an aborted leader which never reached the positive cloud charge. This was followed by some LMA activity at the location of the preceding in-cloud flash. EUCLID did not record any CG or IC pulse either during or before the occurrence of the flash at the tower.

\subsubsection{Skech of the process}

Fig. 14 presents a simplified 2D sketch of the positive flash described in the previous section. The in-cloud negative leader started north from the tower and propagated vertically towards the ground. Again, the possibility of a positive leader propagating in the opposite direction and having been obscured by a stronger radiating negative leader cannot be ruled out. This positive end of leader might have been propagating in the direction of the tower and finally triggered the upward flash. When the in-cloud negative leader reached an altitude of about $3 \mathrm{~km}$, another negative leader was initiated from the tower. Soon after, that LMA activity vanished.

\section{Comparison with self-triggered flashes}

During the $20 \mathrm{~min}$ centered around the first negative OT flash (\#18), 24421 LMA sources were recorded. We define any period of $100 \mathrm{~ms}$ or longer without LMA sources in the covered range as a nonactive period. During these $20 \mathrm{~min}$, the no-activity period amounts to $97.6 \%$ of the total time, showing that the random overlapping of events

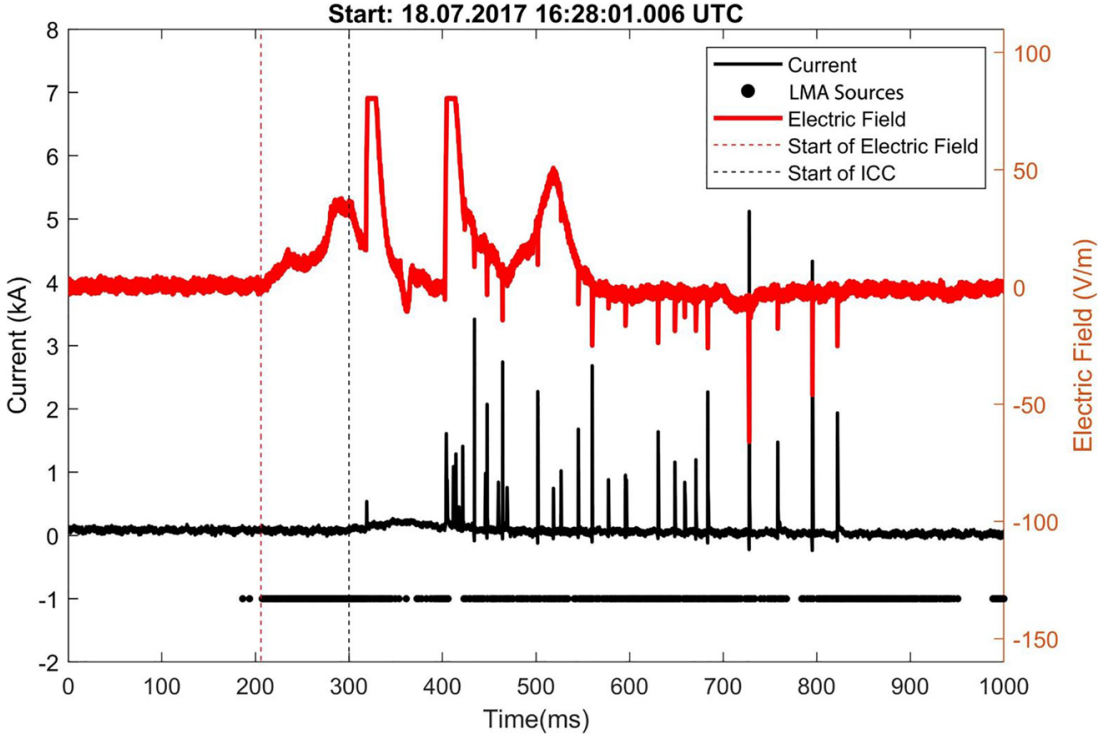

Fig. 8. Electric field at $14.7 \mathrm{~km}$ and current at the tower for the flash recorded on 18.07.2017 at 16:28:01 UTC. The current waveform shown in the figure was filtered with a $1-\mathrm{kHz}$ lowpass filter to better emphasize the initial continuous current. Note that the sign of the current is inverted to emphasize syncronization with the electric field. The flat peak of the electric field plot is due to saturation. 


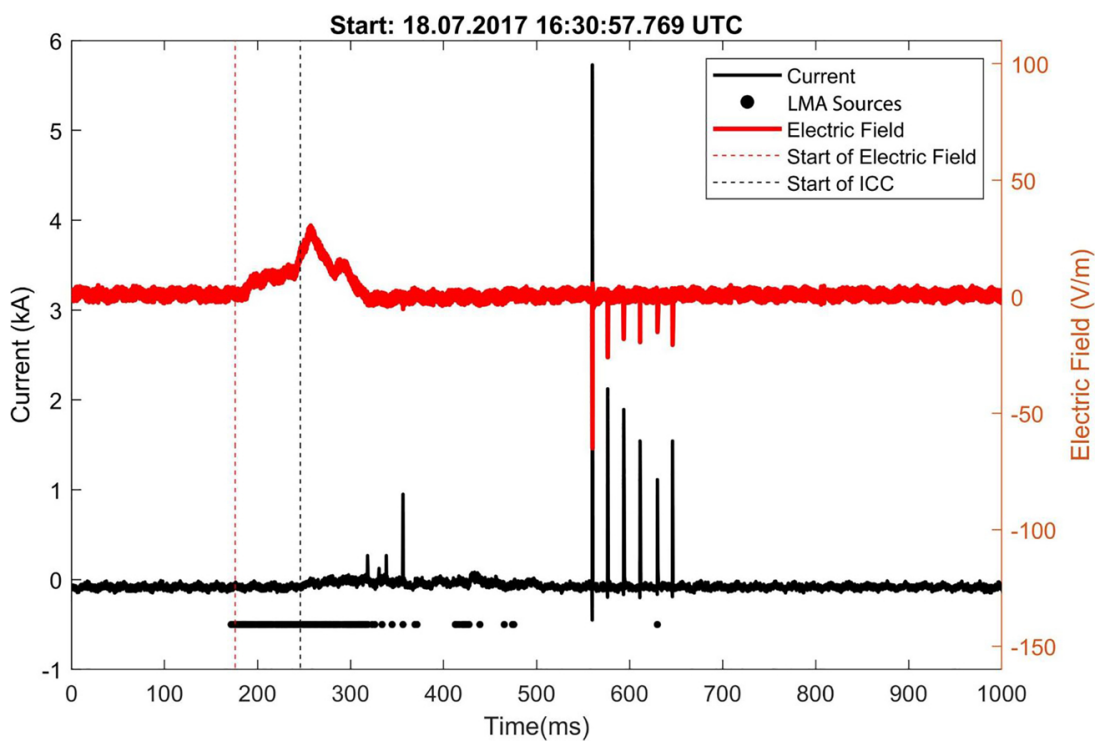

Fig. 9. Electric field at $14.7 \mathrm{~km}$ and current at the tower for the flash recorded on 18.07.2017 at 16:30:57 UTC. The current waveform shown in the figure was filtered with a $1-\mathrm{kHz}$ lowpass filter to better emphasize the initial continuous current. Note that the sign of the current is inverted to emphasize syncronization with the electric field.
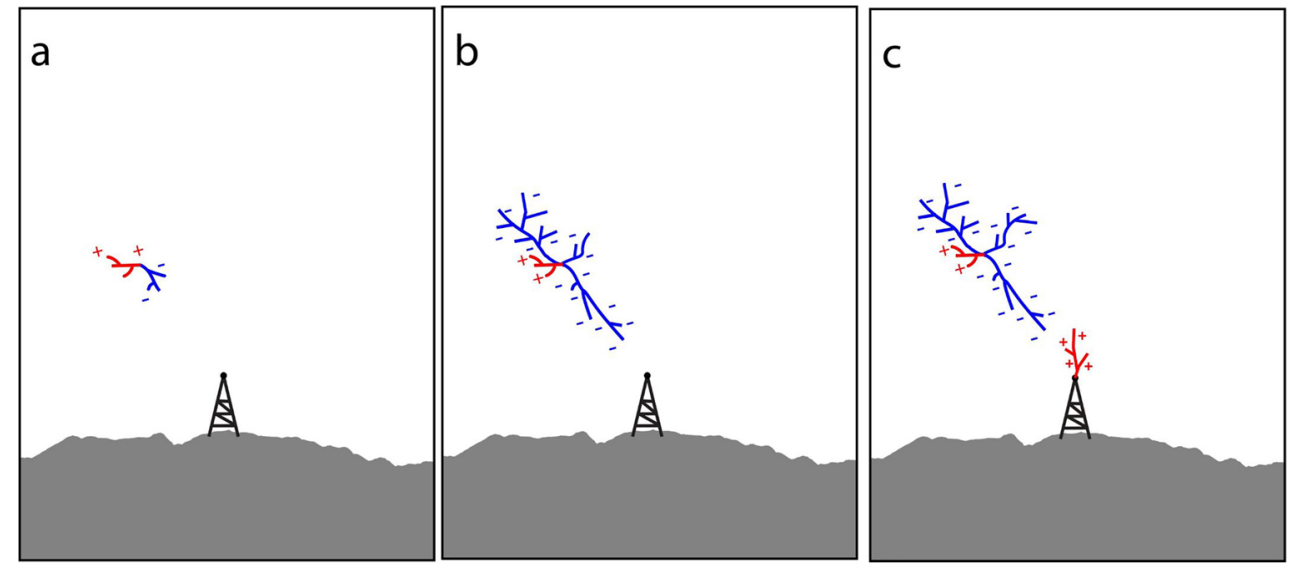

Fig. 10. Sketch of the initial phase of the flash initiated from the Säntis Tower on 18.07.2017 at 16:28:01 UTC. View from the South. Not to scale.
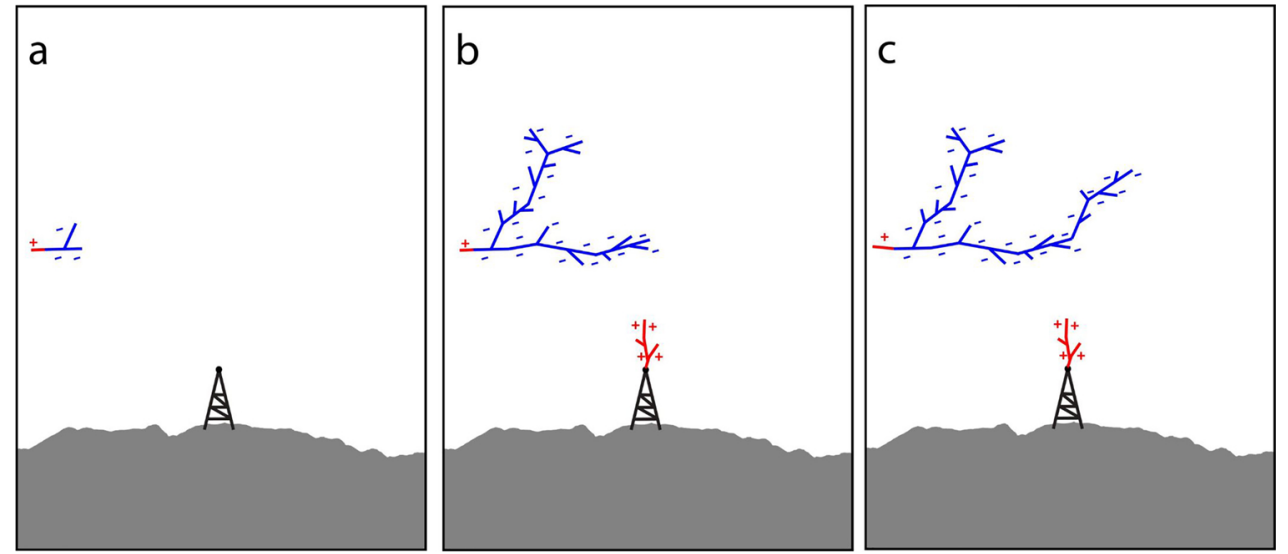

Fig. 11. Sketch of the initial phase of the flash initiated from the Säntis Tower recorded on 18.07.2017 at 16:30:57 UTC. View from the East. Not to scale.

has a probability of $2.4 \%$. For the case of the third negative flash classified as OT based on EUCLID, some of the storm activity occurred outside of the LMA coverage range and we observed a lower LMA activity of $0.68 \%$. The positive OT flash was characterized by an LMA activity of $3.95 \%$. The average LMA activity corresponding to the four OT flashes in the observed period is $2.35 \%$.

ST flashes occurred during less active thunderstorms. LMA activity ranged from 0.01 to $1.67 \%$ with an average value of $0.35 \%$, almost seven times lower than in the case of OT flashes. Interestingly, two flashes (\#5 and \#7) occurred without any LMA activity 10 min prior to the flash.

The charge structure for the two negative OT flashes is characteristic of the typical tripole structure with a large upper positive region. The positive OT was observed during a thunderstorm characterized by a tripole charge structure and larger than usual lower positive region. A detailed analysis of the ST flashes during this campaign can be found in Ref. [40]. It was observed in Ref. [40] that the overall electrical 

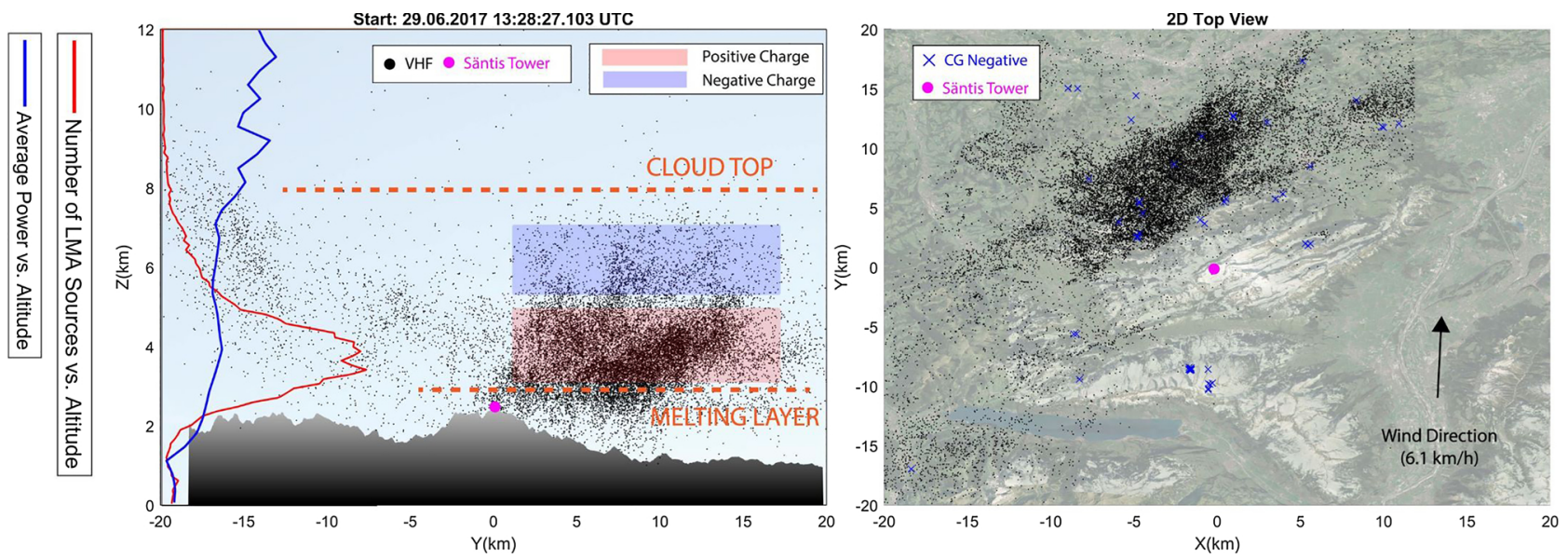

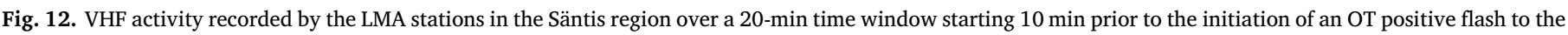

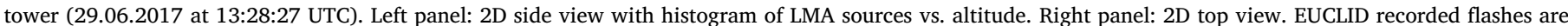

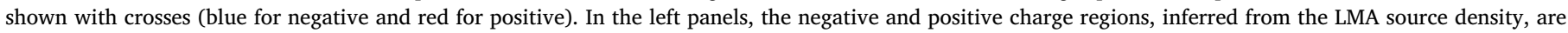
shown, respectively, in blue and red. The position of the tower is shown with a purple marker.
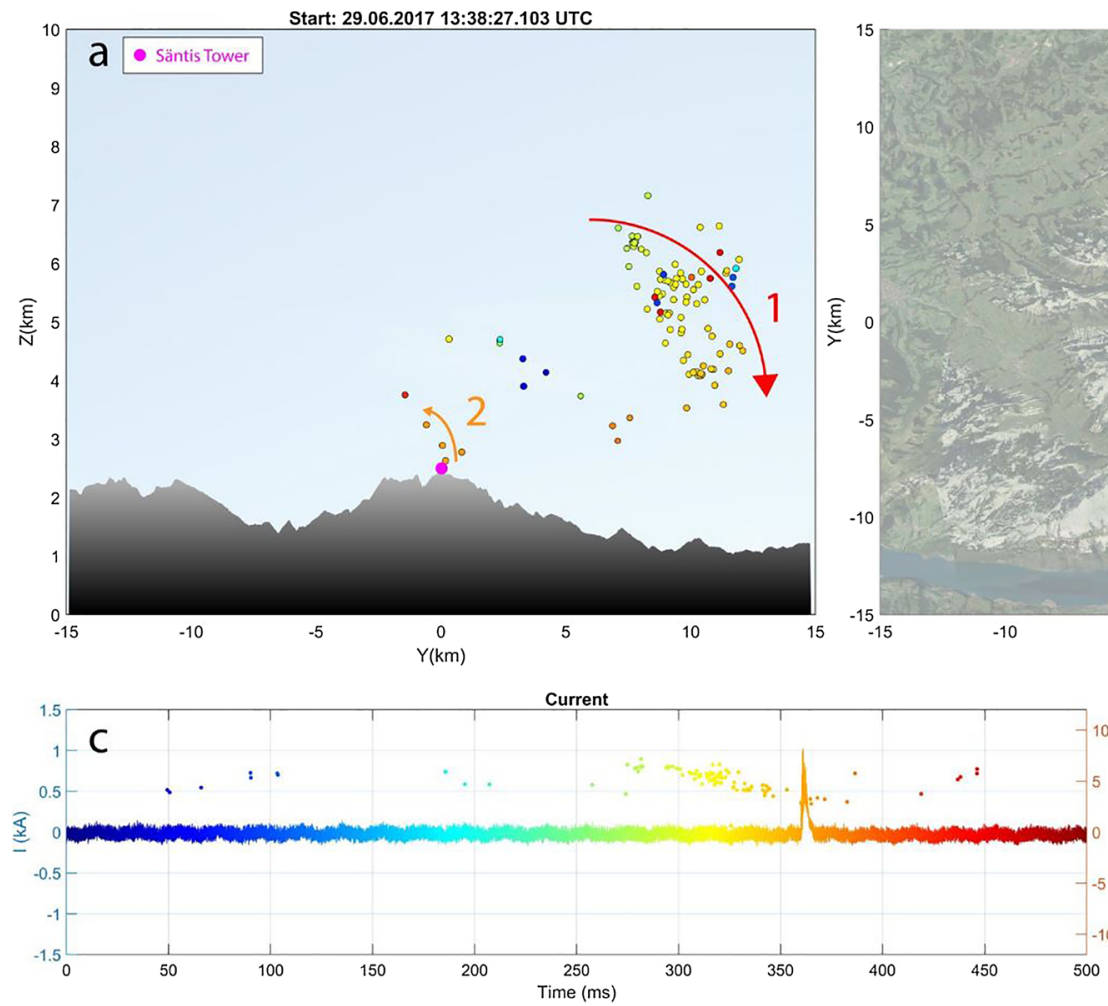
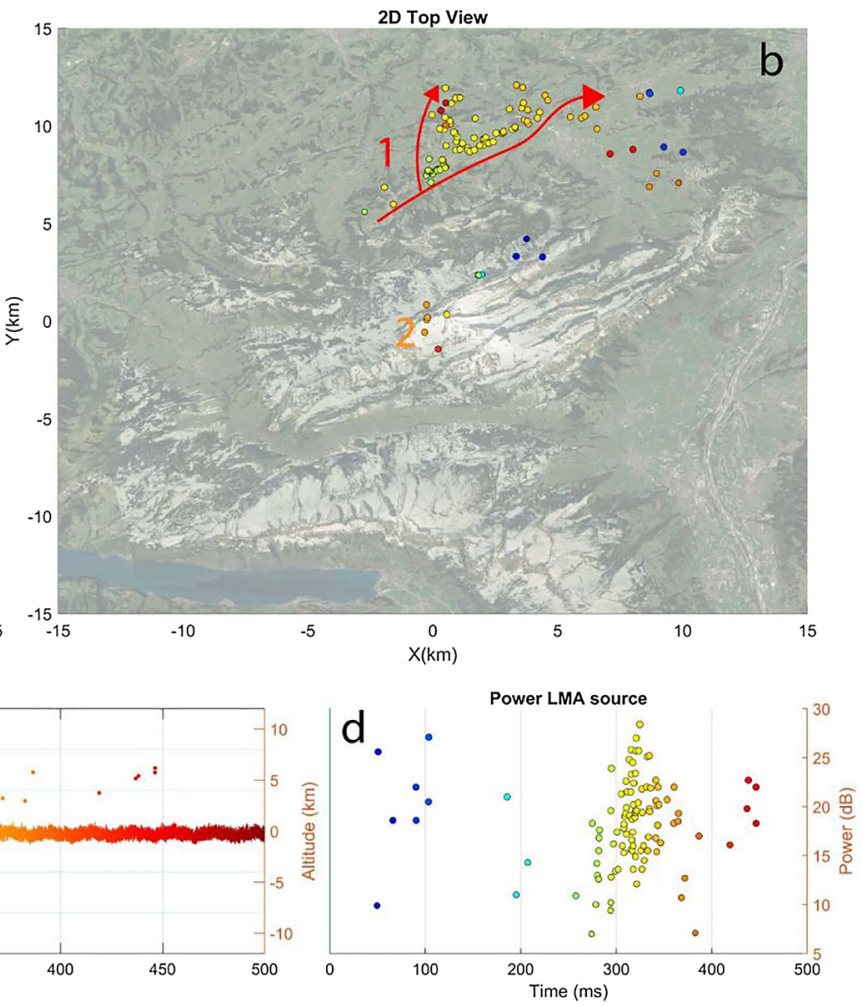

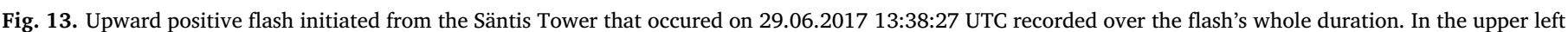

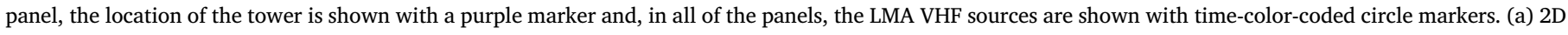

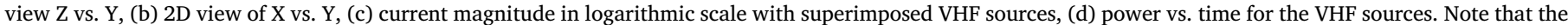
colors were selected for better contrast and they bear no relation to the color-code used for timing. The colored arrows show the development of leaders.

structure consisted of a positive charge in the isothermal layer near the $0{ }^{\circ} \mathrm{C}$, a main negative charge $\left(\sim 4 \mathrm{~km} /-5^{\circ} \mathrm{C}\right)$ and a low density positive above (between $-10^{\circ} \mathrm{C}$ and $-20^{\circ} \mathrm{C}$ ). This corresponds to the typical tripole charge structure [8]. The summary activity of the 20 analyzed flashes is shown in Table 1 . The polarity row shows the polarity of charge transferred to ground.

\section{Conclusions}

We presented in this paper lightning current measurements and LMA data associated with upward flashes observed at the Säntis Tower during Summer 2017. The LMA network consisted of six stations located in the vicinity of the tower at distances ranging from $100 \mathrm{~m}$ to $11 \mathrm{~km}$ from it. We analyzed a total of 20 flashes that were simultaneously recorded by the current measurement system, fast electric field antenna, and LMA in the period from 29.06.2017 to 18.07.2017.

Based on the EUCLID lightning activity in an area within $30 \mathrm{~km}$ from the tower and in a 1-s time window before the start of the flash, only one of the 20 flashes was classified as OT. However, investigations based on the LMA data revealed that 3 more of the flashes were preceded by nearby activity. The results suggest that the number of OT flashes inferred from LLS data can be underestimated. The electric field measurements were available for three OT flashes and, in all of them, a preceding event can be observed. In the four observed OT flashes, the 


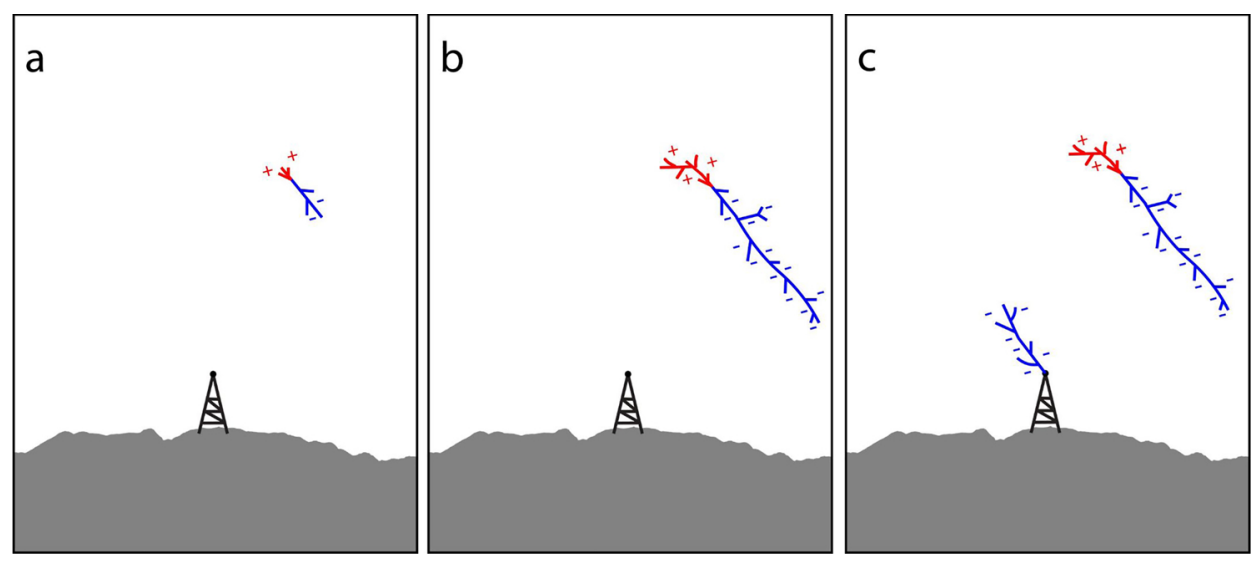

Fig. 14. Sketch of the positive flash initiated from the Säntis Tower recorded on 29.06.2017 at 13:28:27 UTC. View from the East. Not to scale.

events that preceded the tower flash either overlapped completely with the tower flash itself, or the delay between them was at most $100 \mathrm{~ms}$.

We presented a detailed analysis of three OT flashes. The charge structure was inferred from the LMA measurements and the polarity of the leader from the horizontal speed of the leader and the current measurements at the tower. Simplified sketches for three OT flashes were presented. The OT flashes occurred during two different storms. The LMA activity, measured by the number of located sources, was, on average, almost seven times higher compared to that during the ST flashes.

\section{Acknowledgments}

This work was supported in part by the Swiss National Science Foundation (Project No. 200020_175594), the European Union's Horizon 2020 research and innovation program under grant agreement No 737033-LLR, the Spanish Ministry of Economy and the European Regional Development Fund (FEDER) ESP2015-69909-C5-5-R and ESP2017-86263-C4-2-R, and the European Union's Horizon 2020 research and innovation programme under the Marie Skłodowska-Curie grant agreement SAINT 722337.

\section{Appendix A. Supplementary data}

Supplementary material related to this article can be found, in the online version, at doi:https://doi.org/10.1016/j.epsr.2019.106067.

\section{References}

[1] A. Smorgonskiy, F. Rachidi, M. Rubinstein, G. Diendorfer, W. Schulz, On the proportion of upward flashes to lightning research towers, 2011 7th Asia-Pacific International Conference on Lightning (2011).

[2] D. Wang, N. Takagi, T. Watanabe, H. Sakurano, M. Hashimoto, Observed characteristics of upward leaders that are initiated from a windmill and its lightning protection tower, Geophys. Res. Lett. 35 (2008) 2008.

[3] A. Smorgonskiy, A. Tajalli, F. Rachidi, M. Rubinstein, G. Diendorfer, et al., An analysis of the initiation of upward flashes from tall towers with particular reference to Gaisberg and Säntis Towers, J. Atmos. Sol. Terr. Phys. 136 (2015) 46-51.

[4] H. Zhou, G. Diendorfer, R. Thottappillil, H. Pichler, M. Mair, The influence of meteorological conditions on upward lightning initiation at the Gaisberg Tower, 2014 International Conference on Lightning Protection (ICLP), Shanghai, China.

[5] A. Mostajabi, et al., On the impact of meteorological conditions on the initiation of upward lightning flashes from tall structures, 2018 34th International Conference on Lightning Protection (ICLP) (2018).

[6] F. Heidler, M. Manhardt, K. Stimper, Self-Initiated and Other-Triggered Positive Upward Lightning Measured at the Peissenberg Tower, Germany, paper presented at the 2014 International Conference on Lightning Protection (ICLP), 13-17 Oct, Shanghai, 2014

[7] T. Warner, K. Cummins, R. Orville, Upward lightning observations from towers in Rapid City, South Dakota and comparison with National Lightning Detection Network data, 2004-2010, J. Geophys. Res. 117 (19) (2012).

[8] G.V. Cooray, The Lightning Flash IEE, Power \& Energy Series, (2003).

[9] C. Schumann, M.M.F. Saba, T.A. Warner, M.A.S. Ferro, Upward flashes triggering mechanisms, 2017 International Symposium on Lightning Protection (XIV SIPDA),
Natal, Brazil, 2nd-6th October, 2017.

[10] D.E. Proctor, A hyperbolic system for obtaining VHF radio pictures of lightning, J. Geophys. Res. 76 (February (6)) (1971) 1478-1489.

[11] D.E. Proctor, VHF radio pictures of cloud flashes, J. Geophys. Res. 86 (May (C5)) (1981) 4041

[12] D.E. Proctor, R. Uytenbogaardt, B.M. Meredith, VHF radio pictures of lightning flashes to ground, J. Geophys. Res. 93 (October (D10)) (1988) 12683.

[13] B.R. Fuchs, et al., Environmental controls on storm intensity and charge structure in multiple regions of the continental United States, J. Geophys. Res. Atmos. 120 (July (13)) (2015) 6575-6596.

[14] E.W. McCaul, et al., Forecasting lightning threat using cloud-resolving model simulations, Weather Forecasting 24 (June (3)) (2009) 709-729.

[15] D.R. MacGorman, et al., TELEX the thunderstorm electrification and lightning experiment, Bull. Am. Meteorol. Soc. 89 (July (7)) (2008) 997-1013.

[16] W. Rison, R.J. Thomas, P.R. Krehbiel, T. Hamlin, J. Harlin, A GPS-based threedimensional lightning mapping system: initial observations in central New Mexico, Geophys. Res. Lett. 26 (December (23)) (1999) 3573-3576.

[17] R.J. Thomas, et al., Accuracy of the lightning mapping array, J. Geophys. Res. 109 (July (D14)) (2004) D14207.

[18] A. Sunjerga, et al., On the classification of self-triggered versus othertriggered lightning flashes, 2018 34th International Conference on Lightning Protection (ICLP) (2018).

[19] C. Romero, et al., A system for the measurements of lightning currents at the Säntis Tower, Electr. Power Syst. Res. 82 (1) (2012) 34-43.

[20] C. Romero, F. Rachidi, M. Rubinstein, M. Paolone, Lightning currents measured on the Säntis Tower: a summary of the results obtained in 2010 and 2011, 2013 IEEE International Symposium on Electromagnetic Compatibility (2013) 825-828.

[21] M. Azadifar, M. Paolone, D. Pavanello, F. Rachidi, C. Romero, M. Rubinstein, An update on the instrumentation of the Säntis Tower in Switzerland for lightning current measurements and obtained results, CIGRE International Colloquium on Lightning and Power Systems (2014).

[22] C. Romero, F. Rachidi, M. Paolone, S. Member, Statistical distributions of lightning currents associated with upward negative flashes based on the data collected at the Säntis (EMC) Tower in 2010 and 2011, IEEE Trans. Power Deliv. 28 (3) (2013) 1804-1812.

[23] C. Romero, A. Mediano, A. Rubinstein, F. Rachidi, A. Rubinstein, M. Paolone, Measurement of lightning currents using a combination of Rogowski Coils and BDot Sensors, J. Light. Res. 4 (2012) 71-77.

[24] C. Romero, F. Rachidi, M. Rubinstein, M. Paolone, V.A. Rakov, D. Pavanello, Positive lightning flashes recorded on the Säntis Tower in 2010 and 2011, J. Geophys. Res. (2013) 12'879-12'892.

[25] D. Li, et al., On lightning electromagnetic field propagation along an irregular terrain, IEEE Trans. Electromagn. Compat. 58 (February (1)) (2016) 161-171.

[26] A. Mostajabi, et al., LMA observation of upward flashes at Säntis Tower: preliminary results, Joint IEEE International Symposium on Electromagnetic Compatibility \& Asia-Pacific Symposium on Electromagnetic Compatibility (2018) 2-5.

[27] J. Figueras i Ventura, et al., Polarimetric radar characteristics of lightning initiation and propagating channels, Atmospheric Measurement Techniques Discussions, January, 2019, pp. 1-45.

[28] W. Schulz, G. Diendorfer, S. Pedeboy, D.R. Poelman, The European lightning location system EUCLID - part 1: performance analysis and validation, Nat. Hazards Earth Syst. Sci 16 (2016) 595-605.

[29] J.A. López, N. Pineda, J. Montanyà, O. van der Velde, F. Fabró, D. Romero, Spatio temporal dimension of lightning flashes based on three-dimensional lightning mapping array, Atmos. Res. 197 (November) (2017) 255-264.

[30] A. Sunjerga, M. Rubinstein, G. Diendorfer, F. Rachidi, An analysis of the distribution of inter-flash time intervals in the area of the Säntis Tower, 2018 26th International Conference on Software, Telecommunications and Computer Networks (SoftCOM) (2018).

[31] C. Schumann et al., Analysis of the charge distribution and leaders inside the cloud for upward flash initiation 2018 25th ILDC an 7th ILMC Conference.

[32] J.T. Pilkey, et al., Rocket-triggered lightning propagation paths relative to 
preceding natural lightning activity and inferred cloud charge, J. Geophys. Res. 119 (December (23)) (2014) p. 13,427-13,456.

[33] O.A. van der Velde, J. Montanyà, Asymmetries in bidirectional leader development of lightning flashes, J. Geophys. Res. 118 (December (24)) (2013) p. 13,504-13,519.

[34] V. Mazur, L.H. Ruhnke, T.A. Warner, R.E. Orville, Recoil leader formation and development, J. Electrostat. 71 (August (4)) (2013) 763-768.

[35] H.W. Kasemir, A contribution to the electrostatic theory of a lightning discharge, J. Geophys. Res. 65 (July (7)) (1960) 1873-1878.

[36] T.J. Schuur, S.A. Rutledge, Electrification of stratiform regions in mesoscale convective systems. part I: an observational comparison of symmetric and asymmetric
MCSs, J. Atmos. Sci. 57 (July (13)) (2000) 1961-1982.

[37] W.D. Rust, R.J. Trapp, Initial balloon soundings of the electric field in winter nimbostratus clouds in the USA, Geophys. Res. Lett. 29 (October (20)) (2002) pp. 20-1-20-4.

[38] J. Montanyà, O. van der Velde, E.R. Williams, The start of lightning: evidence of bidirectional lightning initiation, Sci. Rep. 5 (October (1)) (2015).

[39] X. Qie, The lower positive charge center and its effect on lightning discharges on the Tibetan Plateau, Geophys. Res. Lett. 32 (5) (2005).

[40] N. Pineda, et al., Meteorological aspects of self-initiated upward lightning at the Säntis Tower (Switzerland), J. Geophys. Res.: Atmos. 124 (n.d.). 